\title{
Adoniran Barbosa e a língua certa do povo
}

\author{
[ Adoniran Barbosa and the people's right language
}

\section{Adriano de Paula Rabelo ${ }^{\mathrm{I}}$}

RESUMO-Um dos aspectos mais interessantes da obra musical de Adoniran Barbosa é a forma como ele estiliza a fala popular. Como se sabe, no Brasil, onde persistem há séculos enormes desigualdades sociais e as classes mais escolarizadas e privilegiadas economicamente demonstram aversão aos pobres, as variantes linguísticas associadas às classes populares têm sido estigmatizadas como "erradas", "inexpressivas", "feias”. Em seus sambas, Adoniran mostra o quanto a fala popular além de ser adequada às situações vivenciadas pelos personagens que protagonizam as histórias tragicômicas de suas canções - é bela, poética, corretíssima. Ao expor a cultura e a linguagem dos estratos da sociedade mantidos na invisibilidade, o compositor exerce, ainda que de maneira involuntária, uma resistência às forças mais retrógradas do país. P PALAVRAS-CHAVE - Adoniran Barbosa; linguagem; preconceito; adequação.

\begin{abstract}
- ABSTRACT - One of the most interesting aspects of Adoniran Barbosa musical work is his stylization of Brazilian popular language. It is well-known that, in Brazil, where immense social inequalities have persisted for centuries and the more privileged extracts of society have shown an explicit aversion to the poor people, linguistic variants associated to the lower classes have been stigmatized as "wrong", "inexpressive", "nasty". In his songs, Barbosa clearly shows how popular language - in addition to being appropriate to the situations experienced by the characters who play the role of tragicomic stories in his songs is beautiful, poetic, and very correct. When the artist exposes culture and language of these lower strata of society, which are maintained invisible, he exerts resistance to Brazil's most retrograde forces, even if this is involuntary. - KEYWORDS · Adoniran Barbosa; language; prejudice; adequacy.
\end{abstract}

Recebido em 27 de fevereiro de 2020

Aprovado em II de setembro de 2020

RABELO, Adriano de Paula. Adoniran Barbosa e a língua certa do povo. Revista do Instituto de Estudos Brasileiros, Brasil, n. 77, p. 37-50, dez. 2020.

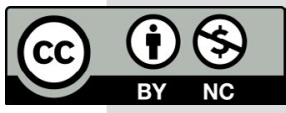

DOI: https://doi.org/Io.II606/issn.23I6-90IX.vIi77p37-50

I Universidade de São Paulo (USP, São Paulo, SP, Brasil). 
Em sua "Evocação do Recife", texto em que recria poeticamente as memórias de sua infância, passada na capital pernambucana em fins do século XIX, Manuel Bandeira realiza uma reflexão mais ampla sobre a cultura brasileira e as transformações nem sempre bem-vindas de nossas cidades em nome do "progresso". Próximo ao desfecho dessa evocação, o poeta erudito, em versos memoráveis, ressalta a influência da linguagem popular em sua formação inicial:

A vida não me chegava pelos jornais nem pelos livros

Vinha da boca do povo na língua errada do povo

Língua certa do povo

Porque ele é que fala gostoso o português do Brasil

Ao passo que nós

O que fazemos

É macaquear

A sintaxe lusíada [...].

(BANDEIRA, I966, p. II6-II7) .

Evitando "macaquear a sintaxe lusíada”, Bandeira construirá toda uma obra que privilegiará a dicção coloquial e muitas vezes o verso livre, utilizando-o com grande maestria técnica. Como ele, a grande maioria dos brasileiros também tem experimentado a vida, em seus primeiros anos, nessa "língua certa" do povo.

Se esse poema remete aos primeiros anos do poeta, ele mesmo, na crônica "A língua nacional", escreve sobre uma recordação muito significativa dos tempos de sua adolescência, passada no Rio de Janeiro:

Quando eu tinha os meus treze anos e andava no Pedro II, vi uma vez Carlos de Laet aproximar-se do guichê do Jardim Botânico e pedir com toda calma: "Me dá uma ida-e-volta”. Foi uma revelação para mim. Laet era escritor de sabor clássico. Se dizia naturalmente "Me dá uma ida-e-volta", isto não podia ser erro no Brasil. Podemos dizer 
isso escrevendo. O que não podemos escrever são construções como esta de Herculano: "Se dizeis isto pela que me destes, tirai-ma que não vo-la pedi eu”. Porque no Brasil [...] não há pessoa alguma, seja o mais primoroso escritor, que construa de semelhante modo essa frase. (BANDEIRA,I968, p. 238-239).

Nessas memórias, Manuel Bandeira recorda um tempo em que as formas de expressão brasileiras ainda lutavam por se fazer presentes na literatura e na produção escrita comum, conferindo maior autenticidade e personalidade própria à linguagem efetivamente praticada no país.

O movimento romântico, no contexto posterior à Independência, muito especialmente na figura de José de Alencar, será o primeiro a não somente buscar um abrasileiramento da linguagem como a teorizar sobre isso. Mais tarde, o movimento modernista fará dessa questão um verdadeiro cavalo de batalha em manifestos, provocações e polêmicas. Mário de Andrade, o principal teórico modernista acerca do uso natural dos recursos expressivos típicos da linguagem brasileira na escrita, chegou mesmo a utilizar uma ortografia bastante peculiar em seus textos, muito influenciada pela fala. Numa carta a Carlos Drummond de Andrade, datada de I8 de fevereiro de I925, ele rechaça, no poeta mineiro, a forma lusitana como as preposições são utilizadas num de seus poemas, refletindo ainda sobre as virtudes da linguagem popular passíveis de serem aproveitadas na expressão literária:

Foi uma ignomínia a substituição do na estação por à estação só porque em Portugal paisinho desimportante pra nós diz assim. Repare que eu digo que Portugal diz assim e não escreve só. Em Portugal tem uma gente corajosa que em vez de ir assuntar como é que dizia na Roma latina e materna, fez uma gramática pelo que se falava em Portugal mesmo. Mas no Brasil o sr. Carlos Drummond diz "cheguei em casa" "fui na farmácia" "vou no cinema" e quando escreve veste um fraque debruado de galego, telefona para Lisboa e pergunta pro ilustre Figueiredo: - "Como é que se está dizendo agora no Chiado: é “chega na estação” ou “chega à estação”? E escreve o que sr. Figueiredo manda. E assim o Brasil progride com Constituição anglo-estadunidense, língua franco-lusa e outras alavancas fecundas e legítimas. [...] O povo não é estúpido quando diz "vou na escola", "me deixe”, “carneirada”, "mapiar”, “besta ruana”, "farra”, "vagão”, “futebol”. É antes inteligentíssimo nessa aparente ignorância porque sofrendo as influências da terra, do clima, das ligações e contatos com outras raças, das necessidades do momento e de adaptação, e da pronúncia, do caráter, da psicologia racial modifica aos poucos uma língua que já não lhe serve de expressão porque não expressa ou sofre essas influências e a transformará afinal numa outra língua que se adapta a essas influências . Então os escrevedores estilizam esse novo vulgar, descobrem-lhe as leis embrionárias e a língua literária, única que tem reconhecimento universal (aqui sinônimo de culto), aparece. (ANDRADE, I982, p. 22-23, grifos do autor)

Ao longo do século XX, a literatura brasileira, em todas as suas formas de expressão, incorporará progressiva e naturalmente o vocabulário, a estrutura, os regionalismos, os coloquialismos e a prosódia que caracterizam as formas de linguagem típicas do Brasil. O epítome e o apogeu desse processo estão, por exemplo, 
na poesia de Carlos Drummond de Andrade e Manuel Bandeira, nas narrativas de João Guimarães Rosa, no teatro de Nelson Rodrigues, que realizavam suas experiências com a linguagem mais ou menos na mesma época em que Adoniran Barbosa criava algumas de suas melhores composições.

Tendo surgido como expressão cultural dos escravos, na Bahia de meados do século XIX, vindo mais tarde a incorporar-se à cultura dos morros e botecos do Rio de Janeiro, o samba já nasceu livre das imposições linguísticas retrógradas e conservadoras das criações eruditas, tendo os compositores e cantores desse estilo musical muito mais liberdade que os escritores. Ainda assim, a partir do momento em que os sambas começaram a ser gravados e consumidos em escala mais ampla que aquela das rodas em espaços da periferia das cidades grandes, tornando-se parte da indústria cultural, muitos sambistas, em busca de inserção social, buscaram dar um tom sublime a suas letras e exibir "correção" gramatical. Apesar disso, elas nunca deixam de ser caixa de ressonância de vocábulos e expressões que antes tinham um alcance muito menor no seio do povo. Em paralelo ao que ocorria na literatura, a música brasileira também teve de passar por um processo de incorporação mais intensa das formas populares de expressão linguística. A obra de Adoniran Barbosa é uma das melhores realizações desse processo.

Se hoje o uso da linguagem brasileira na expressão artística é ponto pacífico, mesmo nas vertentes mais eruditas, isso se deve às elucubrações e à criação de escritores e compositores pioneiros, como os mencionados acima, e tantos outros que surgiram em seu tempo ou vieram depois, trilhando caminhos abertos por eles.

\section{Personagem de Si mesmo}

Adoniran Barbosa formou-se como artista num tempo anterior à televisão, nas décadas de I930 e I940, quando o rádio exercia grande influência cultural. Para os auditórios das grandes estações de rádio, dirigiam-se os talentos em busca de sucesso e popularidade através da música e da dramaturgia então transmitida para o grande público. Tendo tido um início de carreira pouco auspicioso como compositor e cantor, Adoniran acabou por engajar-se como ator em esquetes radiofônicos, interpretando diversos tipos populares, muitos deles criados por Oswaldo Molles, redator radiofônico que exerceu grande influência sobre a forma como ele via o lumpemproletariado da capital paulista. Muito especialmente ao longo dos anos I940, em virtude do sucesso de suas interpretações tanto entre o público presente no auditório da Rádio Record quanto nas casas que recebiam as emissões, Adoniran Barbosa se dedicará muito mais ao trabalho de ator que ao de cantor e compositor. Anos mais tarde, ele atuará também na televisão e no cinema, em várias produções, buscando uma realização mais "séria" no campo da arte dramática, chegando a interpretar o personagem Mané Mole no aclamado $O$ cangaceiro (I953), dirigido por Lima Barreto, Palma de Ouro de melhor filme no festival de Cannes, na França. Sobre a década de I940 e a influência de Molles sobre Adoniran, escreve Ayrton Mugnaini Jr. (2002, p. 48): 
Grande observador dos usos e costumes do povo, Oswaldo Molles foi insuperável na arte de transformar migalhas em banquetes, usando o folclore urbano como matéria-prima para arte comercial da melhor qualidade, tornando frases populares em bordões infalíveis e pessoas reais em personagens marcantes. Sem dúvida, Molles exerceu grande influência sobre Adoniran. Além de criar para ele, sob medida, Charutinho, Zé Conversa e outros tipos que se tornaram clássicos do rádio, foi Molles quem despertou sua vocação de grande cronista e satirista musical.

A partir do início da década de I950, Adoniran Barbosa volta a dedicar-se mais intensamente ao trabalho de compositor de sambas que retratam o cotidiano, a paisagem e o modo de vida dos pobres de São Paulo, cidade que naquele momento passava por um acelerado processo de expansão que ia deixando toda uma massa de deserdados do progresso pelo caminho. Nessa época já são lançadas algumas obras-primas do repertório de Adoniran, como "Saudosa maloca" (I95I), "Malvina" (I95I), “Joga a chave” (I952), “Samba do Arnesto” (I953), "As mariposas” (I955). Aos poucos, na medida em que vai conhecendo o sucesso como compositor e cantor, ele passa a dedicar o melhor de seus esforços na criação de tantos sambas que se tornaram clássicos da música popular brasileira.

João Rubinato era o nome verdadeiro de Adoniran Barbosa. Este se formou pelo primeiro nome de um companheiro de boemia e o sobrenome do cantor Luiz Barbosa, sambista carioca de sucesso nos anos I930, que o paulista admirava. Pela forma como se apresentava publicamente, pode-se dizer que Adoniran Barbosa foi o mais bem-acabado e o mais longevo personagem do ator João Rubinato, que nele forjou uma personalidade artística para uso próprio, confluência de caipiras, italianos e proletários que compunham, em grande medida, o meio popular da cidade de São Paulo entre as décadas de I930 e I960. Esse personagem se caracteriza pelo humor tragicômico, a autoironia, a visão da capital paulista com amor mas sem o ufanismo típico de um período em que ela se tornava rapidamente a cidade mais rica e mais influente do Brasil. A persona do compositor e cantor apresenta-se com frequência identificada à massa de pobres da metrópole (maloqueiros, desempregados, trabalhadores informais, trabalhadores formais explorados pelo capital, vítimas da especulação imobiliária, malandros, vagabundos que perambulam pelas ruas). Seus sambas quase sempre contam histórias tristemente cômicas, comicamente tristes, envolvendo personagens marcantes. Suas melodias privilegiam o tom menor e costumam estender-se por vários compassos sem repetição, evitando o refrão e os paralelismos. Os próprios instrumentos musicais parecem dialogar uns com os outros, sendo que na canção "Mulher, patrão e cachaça” eles chegam a ser personalizados e até a receber sobrenomes.

Adoniran Barbosa, como se vê, impregna-se do espírito de liberdade conquistado pela arte moderna, recriando esteticamente o pequeno, o fragmentário, os seres desprezados e despossuídos, o que está à margem, o desvio, o "mau gosto”. O personagem de si mesmo que ele representava publicamente é uma encarnação desses elementos.

Vale atentar ainda para a figura de talhe chapliniano desse personagem, com seu bigode fino, seu chapéu escuro, seu terno e sua gravata borboleta. Assim como sua 
imagem, seu humor tragicômico está em sintonia aquele que foi popularizado pelo genial ator de cinema britânico no início do século XX.

Em célebre estudo sobre o cômico, o teórico russo Vladimir Propp (I992) estabelece uma classificação dos diferentes tipos de riso. Para ele, entre muitos outros, há uma espécie de riso bom, que se caracteriza pelo envolvimento emocional do ridente com o objeto do riso, sobressaindo os sentimentos de compaixão, empatia e solidariedade. Esse é o tipo de riso que os filmes de Charles Chaplin e as canções de Adoniran Barbosa provocam.

\section{A língua Certa de Adoniran}

Para além da simples mimese da fala do povo, a forma como o compositor recriou essa fala esteticamente é um aspecto fundamental para a comicidade de suas canções. Essa comicidade, como se viu, não resulta da ridicularização dos tipos populares e sua cultura numa sociedade em que os pobres nunca foram reconhecidos como sujeitos. Ao contrário, desperta compreensão e solidariedade pela humanidade dos caracteres nelas retratados.

A naturalidade e espontaneidade com que Adoniran utilizava essa linguagem é algo muito difícil de atingir. Ele mesmo tinha plena consciência disso, como expressa numa entrevista: "Não é fácil escrever errado como eu escrevo, pois tem que parecer bem real. Se não souber dizer as coisas, não diz nada...” (apud MUGNAINI JR., 2002, p. Ioo).

Possuindo um sentido bastante preciso do ritmo e dos cacoetes de fala das pessoas pertencentes aos estratos sociais mais baixos, o compositor paulista realiza, no plano da cidade grande e no âmbito da música popular, algo da dimensão do que Guimarães Rosa realizou no plano do sertão e no âmbito da literatura. Antonio Candido, num texto escrito para a contracapa do LP Adoniran Barbosa, uma compilação de grandes sucessos do artista lançada em I975, trata da importância do trabalho do compositor no plano da linguagem:

Já tenho lido que ele usa uma língua misturada de italiano e português. Não concordo. Da mistura, que é o sal da nossa terra, Adoniran colheu a flor e produziu uma obra radicalmente brasileira, em que as melhores cadências do samba e da canção, alimentadas inclusive pelo terreno fértil das Escolas, se aliaram com naturalidade às deformações normais de português brasileiro, onde Ernesto vira Arnesto, em cuja casa nós fumo e não encontremo ninguém, exatamente como por todo esse país. [...] A fidelidade à música e à fala do povo permitiram a Adoniran exprimir a sua cidade de modo completo e perfeito. (CANDIDO, 2002, p. 2II-2I2). 
Vale a pena fazer um levantamento ${ }^{2}$ comentado de alguns recursos de que Adoniran lança mão para recriar essa língua certa do povo, tão identificada com as idiossincrasias brasileiras, como, por exemplo, arcaísmos, corruptelas, concordância verbal e nominal e pronominalização em desacordo com a gramática normativa, uso de gírias e termos característicos de grupos específicos, coloquialismos e expressões coloquiais, nonsense, termos e expressões macarrônicos em línguas estrangeiras, rimas surpreendentes, nomes próprios e apelidos comuns na linguagem popular, profusão de nomes de lugares - alguns fictícios - da região central de São Paulo, onde se concentra a parcela mais desamparada da população da cidade.

\section{Arcaísmos}

Muitos termos que passam por "erros" do linguajar do povo são, em realidade, formas arcaicas de palavras hoje correntes nos meios considerados "cultos": "candieiro", "alumiar", "frechada”. É comum que grupos menos letrados, que não utilizam no dia a dia a chamada "norma culta”, preservem arcaísmos desse tipo.

\section{Corruptelas}

Devido aos problemas graves de escolarização e educação formal ainda hoje persistentes no Brasil, assim como à menor convivência dos estratos sociais desprivilegiados com a cultura letrada, é muito recorrente, em sua fala, a presença de corruptelas. Na obra de Adoniran, elas são legião: "Arnesto", “Cibide”, “Gerarda”, "nega”, “adifício”, “catuvelo”, "pogréssio”, "deis de intão”, "iscuitei”, "trabaiá, "táubua”, "avuava”, “automóver”, "impossíver”, “nupciar”, “lâmpida”, "muié”, "reiva” (raiva), "paia” (palha), "véio” (velho), "se isquentá”, “fartava” (faltava), "pobrema”, “fia” (filha), "bão", "inté" (até).

\section{Concordância verbal e pronominalização}

Embora na gramática interna da fala popular as concordâncias e pronominalizações sigam regras muito claras, elas contrastam com as formas preconizadas pela gramática normativa, sendo sempre utilizadas quando se quer ridicularizar a expressão dos estratos sociais menos escolarizados. No entanto, em suas composições,

2 Como referenciar cada um dos termos e expressões citados, associando-os às canções de que fazem parte, iria sobrecarregar muito o texto, optou-se por simplesmente listar nesta nota os títulos dessas mesmas canções. São elas: “Saudosa maloca”, “Tiro ao Álvaro”, “Samba do Arnesto”, “Tem das onze”, “Mulher, patrão e cachaça”, “Triste margarida”, “As mariposas”, “Torresmo à milanesa”, “Nóis viemos aqui pra quê?”, “Aguenta a mão, João”, “No morro da Casa Verde”, “Samba italiano”, “O casamento do Moacir”, “Prova de carinho”, “Joga a chave”, “Nego Serafim”, “Apaga o fogo, Mané”, “Iracema”, “Tocar na banda”, “Conselho de mulher”, “Bom dia, tristeza”, “Um samba no Bixiga”, "Viaduto Santa Ifigênia”, “Abrigo do vagabundo”, “'á fui uma brasa”, “Despejo na favela”, "Fica mais um pouco, amor”, “Acende o candieiro”, "Malvina”, "Vide verso meu endereço", "Deus te abençoe”, “Envelhecer é uma arte”, “Não quero entrar”, “No morro do Piolho”, “Pafunça”, “Praça da Sé”, “Rua dos Gusmões”, "Meu amor é o Timão”. 
Adoniran Barbosa mostra que essas formas são muito expressivas nas situações em que elas são empregadas por esses mesmos estratos sociais. E não costumam gerar falta de entendimento: "nóis vai, nóis vorta", "nóis fumo e não encontremo ninguém", "você devia ter ponhado um recado na porta", "a turma da favela convidaram-nos", "se apreparemo para ir", "nóis arranja outro lugar”, "vamo s'imbora”, "troxe” (eu trouxe), "por onde andará Joca e Mato Grosso”, "pode lê", “as vizinha fica louca”, "só dá eu”.

\section{Concordância nominal}

Tal como na concordância verbal, verifica-se que a concordância nominal das formas populares de expressão segue claramente regras de uma gramática interna aos falantes e não provoca falta de compreensão da mensagem: "os hômi", "as muié é as mariposa", "as ropa", "os prato".

\section{Gírias e termos utilizados por grupos específicos}

Muito presentes na fala popular, esses termos (alguns deles até caíram em desuso, outros são ou foram de uso comum apenas na cidade de São Paulo) atestam o dinamismo e a criatividade de expressões que contribuem para revigorar a vertente brasileira do português: "bamba" (bom de samba), "margarida" (funcionária da limpeza pública na cidade de São Paulo), “mariposa” (prostituta), “legal” (ótimo, excelente), "ser uma brasa" (ser muito bom, ser legal), "maloca" (habitação muito precária), "baita” (enorme), "puxa-saco" (bajulador), "bicho" (homem, cara), "dodói” (machucado, na linguagem infantil).

\section{Coloquialismos}

Como suas canções frequentemente possuem uma narração em tom menor, contando acontecimentos tristes de forma bem-humorada, é muito comum que Adoniran cante como se falasse, chegando mesmo a inserir prelúdios falados ou a interromper o canto com intermezzos falados. Assim, esses coloquialismos, que costumam estar presentes mesmo na fala dos mais cultos em situações informais, aparecem frequentemente em suas criações: "prum”, "cuma” (com uma), "pra” (para ou para a), "tô" (estou), "té" (até), "viu?” (ouviu?, pedindo confirmação), "cê”" (você), "eta” (interjeição).

\section{Expressões coloquiais}

Em consonância com a preponderância da coloquialidade nos sambas do compositor paulista, essas expressões de teor popular - que frequentam o cotidiano brasileiro com assiduidade - são presenças recorrentes em suas letras: "nóis num semos tatu" (não somos bobos), "puxar uma palha" (dar um cochilo), "fazer o quilo" (fazer a digestão), "quando vê a coisa preta" (quando está numa situação difícil, complicada), "Deus dá o frio conforme o cobertor" (ditado popular), "aguenta a mão" (sê firme), "com uma mão atrás e outra na frente" (sem nada), "é dureza” (é complicado, é difícil), "é isso aí” (confirmação enfática), "meu bem querer" (meu amor), "minha vida sem 
você não vai” (minha vida sem você não está bem), "Deus te abençoe” (bênção de mãe), "vira-lata sem dono" (sujeito abandonado, rejeitado por todos, perdido na vida), "manhãzinha”, "noitinha” (diminutivos afetivos), "modéstia à parte” (autovalorização), "tire o cavalo da chuva" (desista, perca as ilusões).

\section{Nonsense}

Uma das estratégias mais utilizadas por Adoniran Barbosa para capturar e manter o interesse por suas canções, por seus personagens e pelas histórias que conta, assim como para provocar a comicidade e o riso, é surpreender o ouvinte. O nonsense de algumas expressões semeadas aqui e ali causa um efeito hilariante pelo absurdo que irrompe de repente em meio a uma "normalidade" trivial e opressiva. Além disso, ele faz lembrar a gratuidade dos jogos de palavras infantis, como as parlendas e os trava-línguas, em que se dizem certas frases somente pela diversão de pronunciá-las, sem se preocupar com seus significados: "vamos dar uma de Pirandello", "Violão da Silveira, seu criado”, “Dona Cuíca de Souza”, “Cavaquinho de Oliveira Penteado”, “hai capito, mio San Benedito?”, "a situação aqui tá muito cínica”, "jabá sintético”, "torresmo à milanesa", "tiro ao Álvaro".

\section{Termos e expressões macarrônicos em línguas estrangeiras}

Além de adentrarem também pelo campo do nonsense, esses termos e expressões remetem ao fascínio cultivado no Brasil pelas coisas estrangeiras. Com nosso desastroso ensino de idiomas estrangeiros na educação básica, com a má assimilação das línguas de herança familiar pelos filhos e netos de imigrantes e com as modas recorrentes de inclusão de estrangeirismos em nossa linguagem, era natural que um compositor da estirpe de Adoniran se aproveitasse disso como recurso expressivo e humorístico: "alô, my boy", "charápi” (shut up), "Umas coisas assim em latim:/ 'Qualquer um de vodis aqui presente/ Tem alguma coisa a falar contra esses bodis?”, "Gioconda, piccina mia/ Va brincar in mare nel fondo/ Ma attenzione co il tubarone, hoi visto?/ Hai capito, mio San Benedito?”.

\section{Rimas surpreendentes}

É provável que somente nas letras do compositor paulista se possam encontrar rimas assim, maravilhosamente disparatadas, distorcidas, inesperadas, corretíssimas: "dodói/ my boy", "cachaça/ se acha", "Dito/ ovo frito" "não me amole/ conversa mole", "dando dó na gente/ uma mão atrás outra na frente", "agogô/ infezô", "apertado no pé/ Vila Ré”, "soluçar/ nupciar”, "ponhado/ recado”, “descobriu/ Rio”, "xadrez/ Inês”, "Brás/ mais", "quatro e meia/ as horas vareia”, "quarenta/ aguenta”, "oração/ bão", "os conselho das muié/ se Deus quisé/ Deus não qué”, "ali/ mim”, "Mooca/maloca”, "João Saracura /prefeitura", "muito cínica/vai para as clínica”, "bolso de trás/ como é que faz", "eu faço jus/ apagar a luz", "Irene/ querosene”, "incrível/ combustível”, "Pafunça/ bagunça/ pronunça”, "carabina/ estricnina”, "automóver/ revórver”. 


\section{Nomes próprios}

Tais nomes e apelidos de forte ressonância popular estão em perfeita sintonia com o universo retratado por Adoniran Barbosa: "Nego Serafim”, "Joca”, "Mato Grosso”, "Arnesto”, “Malvina”, “Gervásio”, “Mané”, “Inês”, “João Saracura”, “Dito”, “Terezoca”, "Dona Irene”, "Beleza”, “Cibide”.

\section{Lugares}

Brás, Casa Verde, Jaçanã, Mooca, Bixiga, Tatuapé, Penha, Belém, Vila Maria, Itaquera, Vila Ré, Praça da Bandeira, Praça da Sé, avenida São João, favela do Vergueiro, avenida 23 de Maio, rua Major Diogo, rua dos Gusmões, viaduto Santa Ifigênia, Ermelino Matarazzo, Mogi, Morro do Piolho (lugar fictício)... Sendo um cronista de São Paulo e seu entorno, muito especialmente da periferia e da região central da cidade, onde se concentram os desvalidos da metrópole, o compositor frequentemente faz referência a lugares onde se deram acontecimentos marcantes na vida de seus personagens. Como se vê na lista acima, há bairros, praças, avenidas, ruas, um viaduto, cidades-satélites e até uma comunidade imaginária. Além de expressarem imediatamente a cor local, alguns desses nomes contêm em si um pitoresco e uma graça muito em sintonia com o humor de Adoniran Barbosa. E não se pode esquecer que eles marcam - em alguns casos praticamente determinam - a identidade dos personagens.

\section{DO PRECONCEITO CONTRA A LÍNGUA CERTA}

Apesar de criar sambas de grande qualidade musical desde a juventude, Adoniran Barbosa só obteve sucesso e reconhecimento como cantor e compositor depois dos 40 anos de idade. Em grande medida, isso se deveu ao uso que ele fazia da variante popular e desprestigiada do português brasileiro em suas canções, num tempo em que as conquistas do movimento modernista nas artes ainda não estavam plenamente estabelecidas e num país onde o preconceito contra os pobres é uma das características mais sobressalentes em grande parte dos estratos médios e altos da sociedade. Mesmo quando o compositor já obtinha seus primeiros êxitos, no início da década de I950, o grupo Demônios da Garoa procurou em vão muitas gravadoras, que rejeitaram uma obra-prima como "Saudosa maloca", por causa do linguajar exposto na letra. Numa dessas gravadoras, a Colúmbia, alguém chegou a enxotá-los com a seguinte frase: "Isso é uma vergonha para a música brasileira" (MUGNAINI JR., 2002, p. 80).

Mais tarde, nos anos I970, já com o artista consagrado nacionalmente, a Censura da ditadura militar iria cometer uma estupidez típica de sua nefanda atuação. Antes de lançar um disco com uma coletânea de canções já gravadas e difundidas nas décadas anteriores, Adoniran submeteu suas letras para avaliação e parecer dos censores, certo de que não haveria nenhum problema com elas, pois não apresentavam nenhuma mensagem de teor político direto. 
No entanto, de maneira surpreendente, as faixas "Despejo na favela", "Tiro ao Álvaro", “Um samba no Bixiga”, “O casamento do Moacir” e "Já fui uma brasa” foram proibidas. Recentemente o material com essas letras - datilografadas, com os pareceres dos censores às margens, manuscritos a caneta - foi resgatado nos arquivos da Censura Federal. Os termos que foram considerados mal escritos estão grifados ou circulados, ladeados por comentários, com a palavra "Vetada" escrita em caixa-alta e/ou sublinhada e os carimbos dos burocratas do regime autoritário. O parecer sobre "Tiro ao Álvaro", por exemplo, emitido em 27 de abril de I973, é um atestado de ignorância e desqualificação da censora Eugênia Costa Rodrigues, que o assina. Sem nenhuma compreensão do tipo de personagem que é o sujeito da canção, sem cogitar da habilidade do compositor para estilizar a fala popular, ela circula as palavras escritas com "erros". Ao lado da letra, ela rabisca seu parecer: "A falta de gosto impede a liberação da letra". O que seria essa vaga "falta de gosto" senão uma expressão do preconceito da censora? Numa folha separada, há uma sugestão de que os "erros" do compositor, em "Já fui uma brasa" e "Tiro ao Álvaro", sejam consertados, e que as letras sejam novamente submetidas à Censura para possível liberação. Ante a inépcia desses pareceres, Adoniran resolveu não lançar seu disco naquele ano. Somente em I975, quando começava a chamada "abertura política" do regime, as cinco canções puderam ser gravadas como foram escritas.

Uma obra como a de Adoniran Barbosa, para além de seu óbvio valor estético, tem ainda a possibilidade de fomentar o debate sobre o chamado preconceito linguístico, que ainda subsiste amplamente no Brasil, mesmo nas salas de aula e nos meios de comunicação de massas, onde se espera uma defesa clara dos valores da democracia e da cidadania. Nas aulas de português, tem persistido uma abordagem de caráter normativo-prescritivo de uma língua abstraída de situações concretas. Recentemente assistimos ao fenômeno dos professores de português que ocupavam espaço em programas de televisão e colunas de jornal ensinando as formas "corretas" de se expressar, com exemplos de "erros" in abstracto colhidos justamente em canções populares e em entrevistas com pessoas nas ruas das cidades grandes. E também houve uma onda de publicação de livros com títulos do tipo Não erre mais! ou Manual da falta de estilo, de autoria de gramáticos prescritivos, que se apresentavam como guias iluminados ensinando o "bom uso" do português "de uma vez por todas".

Conforme o Dicionário Houaiss da língua portuguesa (200I, p. I824), preconceito é "qualquer opinião ou sentimento, quer favorável quer desfavorável, concebido sem exame crítico"; "ideia, opinião ou sentimento desfavorável formado a priori, sem maior conhecimento, ponderação ou razão"; "atitude, sentimento ou parecer insensato, especialmente de natureza hostil, assumido em consequência de generalização apressada de uma experiência pessoal ou imposta pelo meio; intolerância”. Quanto à expressão "preconceito linguístico" especificamente, o mesmo dicionário traz a seguinte definição: "qualquer crença sem fundamento científico acerca das línguas e de seus usuários, como, p. ex., a crença de que existem línguas desenvolvidas e línguas primitivas, ou de que os povos indígenas da África e da América não possuem línguas, apenas dialetos”. 
Na sociolinguística, há muito tempo já é ponto pacífico que não existem maneiras de falar corretas ou erradas em si. Dentro de uma comunidade linguística, convivem diversas variantes do idioma, que são uma expressão das diferentes culturas que ali existem, com seus modos de vida e suas tradições. A própria "norma culta" ou "norma padrão", como assim é chamada, a de maior prestígio social, apresenta variações conforme situações e grupos que a utilizam em comunicações públicas ou privadas de natureza formal. Em situações informais, mesmo os mais escolarizados empregam uma linguagem distinta daquela utilizada em seu trabalho, na comunicação com autoridades ou em eventos públicos, como reporta Manuel Bandeira no episódio envolvendo Carlos de Laet. Ademais, se tomarmos como referência as gramáticas normativas utilizadas nas escolas brasileiras, nos depararemos com uma norma "culta" ou "padrão" extremamente conservadora, ainda muito atada a usos correntes em Portugal.

Ao longo de séculos tem havido um prejulgamento das variantes mais informais e associadas às classes sociais mais baixas. Tais classes têm menos acesso à educação formal; e aquela a que elas conseguem ter acesso é, em geral, de péssima qualidade. Como parte da aversão aos pobres que impera entre as elites intelectuais e econômicas no Brasil, mas também como parte da discriminação de determinadas regiões, determinadas culturas, determinados grupos marcados por seu fenótipo ou seu comportamento sexual, ainda é comum ouvir que alguém ou algum grupo de pessoas "fala errado", "fala mal o português", "tem um modo vulgar de falar", "tem um sotaque horrível". Junta-se a isso uma tendência a supervalorizar a língua escrita em relação à língua falada, como se elas competissem entre si e não fossem duas modalidades distintas, cada uma delas servindo a situações e objetivos específicos. Ao tratar dos métodos e do conteúdo da disciplina Língua Portuguesa na escola, o linguista Ataliba Castilho defende, na contramão do grafocentrismo, a língua falada e sua variedade como ponto de partida para uma reflexão sobre o fenômeno linguístico que pode ser fascinante, envolvente e libertadora:

Ora, se essa disciplina se concentrasse mais na reflexão sobre a língua que falamos, deixando de lado a reprodução de esquemas classificatórios, logo se descobriria a importância da língua falada, mesmo para a aquisição da língua escrita. [...]

O ponto de partida para a reflexão gramatical será o conhecimento linguístico de que os alunos dispõem ao chegar à escola: a conversação. O ponto de chegada será a observação do conhecimento linguístico do "outro", expresso nos textos escritos de interesse prático (jornais, revistas de atualidades) e nos textos literários, cujo projeto estético será examinado. A proposta se fixa na língua que adquirimos em família, como um ponto de partida mais autêntico. Com ela nos confundimos, e nela encontramos nossa identidade. Ver considerado na escola seu modo próprio de falar, ser sensibilizado para a aceitação da variedade linguística que flui da boca do outro, saber escolher a variedade adequada a cada situação - estes são os ideais da formação linguística do cidadão numa sociedade democrática. (CASTILHO, I998, p. I3; p. 2I).

A questão central que as mentalidades autoritárias e discriminatórias não conseguem 
perceber quando elegem variedades linguísticas boas ou ruins, bonitas ou feias, expressivas ou inexpressivas, corretas ou erradas em si, está justamente no tipo de linguagem adequado a cada situação. Se o personagem Adoniran Barbosa ou os personagens que aparecem em suas canções fossem diplomatas numa cerimônia ou doutores defendendo uma tese em Filosofia ou Direito numa universidade qualquer, a linguagem que falam seria de fato inadequada. Sendo quem são, vivendo como vivem, sofrendo a injustiça social que grassa no Brasil, eles só podem falar como falam. E como falam bem! Como falam de maneira certa, precisa e bela, com grande poesia, exprimindo uma humanidade riquíssima a despeito da carência quase absoluta em que levam suas vidas.

Sem apresentar nenhuma intenção de produzir uma arte de cunho social ou político explícito, sem pretender fazer denúncia das condições em que sobrevive a maioria do povo brasileiro, Adoniran Barbosa, ao narrar histórias, expor tipos, modos de vida e principalmente a linguagem das classes populares, exerce resistência, ainda que involuntária, contra as forças que trabalham para excluir, silenciar e tornar invisíveis tantos milhões de brasileiros a quem estão negados os direitos da cidadania e a participação numa sociedade verdadeiramente democrática.

\section{SOBRE O AUTOR}

ADRIANO DE PAULA RABELO é pós-doutor em Teoria Literária pela Universidade Estadual de Campinas (Unicamp) e em História pela Universidade de São Paulo (USP) e autor de O amoré um abismo furtivo (Aglaia, 2020), além de tradutor e organizador de Esta agonia é o nosso triunfo: as cartas de Sacco e Vanzetti (Edições 70, 2020).

e-mail: aprabelo@hotmail.com

https://orcid.org/oooo-0002-2747-6186

\section{REFERÊNCIAS}

ANDRADE, Carlos Drummond de (org.). A lição do amigo: cartas de Mário de Andrade a Carlos Drummond de Andrade. Rio de Janeiro: José Olympio, I982.

BAGNO, Marcos. Preconceito linguístico: o que é, como se faz. São Paulo: Loyola, I999.

BANDEIRA, Manuel. Estrela da vida inteira: poesias reunidas. Rio de Janeiro: José Olympio, Ig66.

BANDEIRA, Manuel. Andorinha, andorinha. Rio de Janeiro: José Olympio, I968.

CANDIDO, Antonio. Textos de intervenção. Seleção, apresentação e notas de Vinicius Dantas. São Paulo:

Editora 34/Duas Cidades, 2002. (Coleção Espírito Crítico).

CASTILHO, Ataliba Teixeira de. A língua falada no ensino de português. São Paulo: Contexto, I998.

INSTITUTO ANTONIO HOUAISS. Dicionário Houaiss da língua portuguesa. Rio de Janeiro: Objetiva, 2001. MUGNAINI JR., Ayrton. Adoniran: dá licença de contar... São Paulo: Editora 34, 2002. 
PROPP, Vladimir. Comicidade e riso. São Paulo: Ática, I992.

ROCHA, Francisco. Adoniran Barbosa: o poeta da cidade. São Paulo: Ateliê, 2000.

VALENTE, André Crim. A linguagem nossa de cada dia. Petrópolis: Vozes, I997. 